\title{
Evaluación y alternativas de la banca de fomento estatal para la democratización del crédito en El Salvador*
}

\author{
Carlos P. Martínez \\ Eric W. Larreynaga
}

\section{Introduccion}

En la esfera económica, la estrategia puesta en marcha por el actual gobierno para el quinquenio 1989-1994, se orienta al establecimiento de una economía de libre mercado y, consecuentemente, se están aplicando medidas tendientes a la liberalización económica.

En este contexto, se está llevando a cabo un proceso de desregularización y privatización de las instiluciones del sistema financiero. Ello lleva a reflexionar acerca del luturo de aquellas otras instituciones tinancleras que, tlpilicadas como de fomenlo, trabajan con políticas que interfieren en el libre juego del mercado de tactores. En este trabajo se estudian estas instituciones de fomento con el fin de perfilar un proceso de democratización del crédito.

Podrán existir diferentes modalidades que representen una alternativa para lograr la democratización del crédito en El Salvador. Sin embargo, la existencia de aquellas instituciones destinadas a acelerar el desa-

- El presente artlculo es una sintesis de los principales aspectos del trabajo de tesis para optar al grado de Licenciado en Economía, Elaborado bajo la asesorla de Herman Navas. 
rrollo económico garantizando los recursos tinancieros para suplir las necesidades de capital de trabajo o para ampliar la capacidad instalada, complementados por una asistencia en general, es una altemativa para logrario, que debe ser aprovechada.

Consideramos que una banca de lomento es el rellejo de la creciente necesidad de un rápido desarrollo económico y de la búsqueda de mélodos y formas allernativas de tecnificación, para ser ulilizados en aquellos lugares y sectores estralégicos donde ese tan ansiado desarrollo no parece estar realizándose por si solo con la rapidez deseada.

Estas consideraciones nos llevaron a elegir a la banca de fomento como la mejor allernativa para echar a andar un proceso de democratización del crédito. Antes de especificar las allernativas de democratización del crédito, hemos realizado una evaluación de las actividades financieras de las siguientes instituciones: Federación de Cajas de Crédito (FEDECCREDITO), Banco de Fomento Agropecuario (BFA) y Fondo de Financiamiento y Garantia para la Pequefa Empresa (FIGAPE), por ser las instituciones más representativas en esta área.

En cuanto a los sectores estratégicos antes mencionados, fueron focalizados en esa nueva "estruclura empresarial" surgida como fenómeno económico-social que, dado el tipo y tamano de la actividad desarrollada, se ha distinguido por su "informalidad", y por ser de un tamano tan pequeño que se denominó micro y pequena empresa, pero que ha constiluido un importante sustento de la economia salvadorefa, especialmente a lo largo de la década de 1980.

Aunque la experiencia sobre el funcionamiento de la banca de fomento en El Salvador parece justificar las crílicas del pensamiento neoliberal sobre la intervención estalal, la corrección de sus deficiencias y la polencialización de sus beneficios en el marco de una estrategia integradora al sistema financiero en su conjunto, podrian constituir una superación de las políticas financieras neoliberales.

\section{La banca de lomento como una alternativa para la democratiza- clón del crédito}

El sector informal que aglutina a los microempresarios, se ha constituido en un paliativo del problema del desempleo y la pobreza en el pals y se convierte en el sector objetivo de la atención de la Banca de Fomento (FEDECCREDITO, BFA, FIGAPE).

La razón es que la pequena y microempresa representan el sostén de la economia nacional, pues absorben la mayor parte de la fuerza laboral. De acuerdo a MIPLAN para 1978 y 1979 ya exislian 346,388 
Irabajadores independientes, de los cuales 198,479 estaban ubicados en la agricultura, 11,098 en el comercio, 64,042 en la manufactura y los 72,769 restantes en el transporle, servicios y construcción. ${ }^{1}$ Para 1987 la microempresa representaba e $94 \%$ de todas las empresas en EI Salvador, y el $39 \%$ de los empleos no agricolas. ${ }^{2}$

Sin embargo, pese a tener una significaliva participación en el quehacer económico del pais, la microempresa como característica del sector intormal, se entrenta a diversos problemas que limitan su desarrollo. Entre estos problemas se encuentran:

a) Disponibilidad insuliciente de recursos financieros. La Banca Comercial dedica únicamente el $2 \%$ de su cartera para lomentar actividades de microempresarios.

b) Lograr el financiamienlo conlleva a cubrir una serie de requisilos que muchas veces el empresario no posee, por lo que la garantia en el olorgamiento del crédilo es insuficiente y la microempresa no logra constituirse en sujelo de crédito.

c) Inadecuado tinanciamiento, por el alto coslo que genera a las instiluciones financieras el olorgar créditos de bajos montos.

d) Deficiencia en la comercialización de sus productos, al no contar con canales de distribución adecuados.

e) Falta de capital para adquirir materias primas de calidad aceptable, lo que imposibilita competir en el mercado.

\subsection{Esquematizaclón de un modelo de banca de fomento}

\subsection{1. ¿Qué es una banca de lomento?}

Para los efectos de nuestra invesligación una Banca de Fomento deberá concebirse como una institución que, contando con la participación acliva del Estado, se dedique primordialmente a la atención de los micro y pequefios empresarios, por considerarse sectores estratégicos, dado su peso y participación en la economia del pais, y destinada a convertirse en un apoyo para lograr el desarrollo de los mismos, poniendo a su disposición capital y asistencia en general.

En esle sentido una Banca de Fomento debe proyectarse para servir

1. Sevilla, Manuel. "Visión global de la concentración económica en El Salvador". Boletin de Ciencias Económicas y Sociales. Mayo-Junio de 1984: Año VII, No. 3. Pág. 165.

2. Informe Sandlord, "Pobreza, conflicto y esperanza: un momento crítico para Centroamérica". Editorial Tecnos. 1999. Pág. 66. 
como "medio de movilizar recursos y capacidades", canalizándolos hacia estos seclores que no han lenido una oportunidad para desarrollarse - que, teniéndola, no han recibido la asistencia suficiente y necesaria para lograrlo, convirtiéndose asi en una verdadera alternaliva de un proceso de democratización del crédito.

\subsubsection{Objellvos}

Puededen sefalarse los siguientes objelivos para una banca de fomento:

a) Propiciar medios económicos y asistencia técnica que permitan un desenvolvimiento de las empresas que son objelo de la concesión de créditos y de un proceso de democratización del crédilo.

b) Contribuir al desarrollo económico-social del pais.

c) Desarrollar y financiar proyectos de especialización que tengan por objeto el mejoramiento del bieneslar material de la población objetivo, en particular y de todos los salvadorefios en general.

d) Financiar a los micro y pequenos empresarios para que puedan ampliar sus operaciones, modernizar sus procesos de producción y cambiar su estruclura productiva.

\subsubsection{Fuentes y usos de fondos}

Una Banca de Fomento deberá obtener sus fondos primordialmente de las siguientes fuentes:

a) El Estado, ya que su ayuda es la pieza principal de la existencia y crecimiento de la instilución. En este sentido no debe limitarse a dar única y exclusivamente un aporle inicial para lograr constituirla, sino también debe existir un programa de seguimiento a fin de que sea un respaldo financiero.

b) Organismos inlemacionales. La Banca de Fomento lambién puede obtener, y de hecho lo hace, londos de organismos internacionales que se especializan en este tipo de concesiones. Entre ellos hay que mencionar al Banco Mundial, el BID y AID.

c) Fuentes propias. Esta fuente la conslituyen lodos aquellos usuarios de la inslitución que, medianle la concesión y reembolso de créditos, proporcionen los recursos financieros necesarios para su mantenimiento y crecimiento institucional. 


\subsubsection{Parámetros claves}

Un modelo de Banca de Fomento debe responder a los objetivos inicialmente planteados; sin embargo, la existencia de propósitos que pueden pretenderse abordar sugiere que exisle loda una gama de problemas. Todos eslos problemas representan lactores condicionantes del funcionamiento de la institución. Por ello, consideramos que los parámetros claves que deben regir a la hora de implementar una Banca de Fomenlo son:

a) Tasa de crecimiento: Tener una lasa de crecimiento acorde al ritmo de la economia. Esta premisa representa el impacto que la institución ha tenido en la salistacción de las necesidades crediticias de su poblaciónobjetivo. Asimismo, indicará el grado de fortalecimiento institucional que, de ser la misma cuantía al crecimiento del PIB real, estaría asegurando su permanencia en el tiempo.

b) Rentabilidad: Una Banca de Fomento no alcanzará su objetivo de ser una altemativa para la democratización del crédilo si dedica exclusivamente su limitado capital a las solicitudes que merezcan pasar por cauces estrictamente bancarios, sin tener en cuenta la finalidad a que sirve y, a la vez, como Banca no puede ignorar los aspectos financieros de las propuestas y correr el riesgo de que su capital quede menguado. ${ }^{3}$ La distinción entre estos aspectos - la rentabilidad financiera versus los objetivos de desarrollo- es un punto medular, sobre todo en el caso que los proyectos si van a reportar beneficios para la economia como lo es el aumento del empleo. Esta rentabilidad de cara a lograr programas de desarrollo de tipo financiero-crediticio y en forma autofinanciable debe permitir, al menos, la recuperación de los costos de operación. En tal sentido, el punto de referencia debe ser la lasa de interés que los bancos comerciales pagan por los depósitos a 180 dias, ya que esto representa el costo de oporlunidad de estos recursos crediticios."

c) Solvencia: También se necesita que la Banca de Fomento sea solvente. Ello requiere que se encuentre en capacidad de hacer trente a sus obligaciones, tanto social como financieramente. La solvencia es la capacidad para pagar con sus activos valuados por su valor de realización, sus pasivos con terceros. Para ello deberá conciliar su política con la actual Ley de Bancos. ${ }^{5}$ En esle sentido debe mantener en todo mo-

3. Monkarz, Raúl. "Moneda y Banca". La Banca de Desarrollo. Cap. 20. Pág. 232.

4. Sugerido por el Lic. Herman Navas como parámetro para establecer el correspondiente costo de oportunidad.

5. Ley de Bancos y Financieras. Diario Oticial, Tomo No. 311. San Salvador, miércoles 22 de mayo de 1991. No. 92. 
mento una relación de por lo menos el $8 \%$ entre su fondo palrimonial y sus activos, así como del $4 \%$ siempre de su patrimonio con relación a sus obligaciones o pasivos lolales. De manera contraria, al caer debajo de estos limites, le implicaría menguar su capacidad de dar crédito, ya que al disminuir sus activos, la liquidez es menor $y$, en tal sentido, la disponibilidad de recursos para conceder crédilo es menor. ${ }^{6}$

d) Absorción de un número de usuarios que justifique su existencia: En sus primeros pasos una Banca de Fomento no estará en capacidad de absorber la totalidad de los demandantes del crédito, por ello debe crecer institucionalmente vía la implementación de un proceso de democratización del crédito. Pero además debe contar con los recursos suficientes para atender crediticiamente al mayor número de usuarios, de tal forma que justifique su existencia. Esta mayoria deberá ser entendida al menos como el $50 \%$ de los demandantes potenciales de crédito y deberá ser alcanzada en un plazo de tres ańos, conlados a partir de su creación, o el $10 \%$ anual.

Un aspecto esencial del modelo del trabajo de investigación es la definición de la democratización del crédito. Y sobre el particular habría que decir en primer lugar que se trala de un proceso, es decir algo permanenle a través del liempo.

En segundo lugar, un proceso de democratización del crédilo, deberá concebirse como aquella siluación en donde instilucional o legalmente eslos seclores estratégicos, focalizados en el sector intormal de la economía, tengan una igualdad de oportunidades para optar a un determinado lipo de crédito.

Pero además hay que agregar que esla situación no es una condición suliciente, pero si sumamente necesaria. Por ello un proceso de democralización del crédito debe significar no sólo la oportunidad de colocar una solicilud en una institución financiera, sino también tener la certeza de que ese crédilo se va a concretizar en la concesión del mismo.

\section{Evaluaclón de la banca de fomento estatal en El Salvador}

\subsection{Las insthuciones fInancleras de fomento en EI Salvador}

En 1961 el BCR fue nacionalizado propiciando la captación de recur-

6. Estos valores surgen inicialmente en la Comunidad Económica Europea, donde los bancos de Francia, Inglaterra y Francia, buscando la integración económica, deciden unilormizar los niveles de solvencia financiera mediante el Acuerdo de Basilea. El Salvador, como parte integrante de ese proceso de globalización de la economía internacional, lo hace suyo y se uniformiza. De ahl que se encuentre en la actual Ley de Bancos. 
sos exlernos para financiar programas de desarrollo productivo. Entre estos, se pensó en el desarrollo del sector agropecuario con recursos del exterior, por to que en diciembre de 1961, surge una entidad de carácter oficial de crédito supervisado, exclusivamente orientado a la agricultura, a la cual se le denominó Administración de Bienestar Campesino (ABC). Esla entidad tenía objetivos suficientemente amplios de asistencia técnica y financiera, con la idea de incrementar la productividad del sector.

En 1966 nace la idea de cooperativa de ahorro y crédito, como una vía de acceso para satislacer las necesidades de financiamiento de salvadorenos con aptiludes produclivas en la cuantia y condiciones demandadas. Es así como surge la Federación de Asociaciones Cooperativas de Ahorro y Crédilo de El Salvador (FEDECACES), con el objeto de fortalecer este movimiento cooperativo.

A partir de 1970 se manifiesta la importancia de la pequena empresa en El Salvador, por lo que existia la inquietud de propiciar un financiamiento adecuado y oporluno que solventara el obstáculo de las condiciones del crédito existente, que en ese entonces no permilía el tortalecimiento de la pequefia empresa del tipo industrial.

Es asi como surge en el año de 1973, el Fondo de Financiamiento y Garantia para la Pequeña Empresa (FIGAPE), como una institución que sustiluye al Fondo de Garantia para la Pequefia Empresa Industrial (FOGAPI), con el objeto de apoyar a esta actividad.

En la década de 1970 se realizaron evaluaciones relerentes a la evolución de la asistencia crediticia y su impacto en la economia salvadorena. EI BCR tuvo un papel determinante al coordinar los estudios sobre crédito agricola, donde se delerminó que el impacto de la $A B C$ no habia tenido el resultado esperado para el seclor agropecuario. Ante ello, en 1973 surge el Banco de Fomento Agropecuario (BFA), como una institución oficial dedicada a desarrollar la producción agricola, la agro-industria y los productos pecuarios, que sustituiria a su antecesor el ABC.

Luego, en 1980, es el marco legal el que promueve una reorientación del crédilo, a través de la nacionalización de la Banca, pretendiendo "hacer llegar el crédito primordialmente a la pequena y mediana empresa, lavoreciendo la capacidad empresarial, a través del crédito en función social, y promover el bieneslar general de la población y el desarrollo económico y social del pais" ?

7. BFA. "Planteamiento General sobre el Crédito Agropecuario en El Salvador". 06/85 
Para esta época, ya se contaba con tres instituciones sumamente importantes, destinadas a constituirse en fuentes de financiamiento para aquellos sectores de micro y pequenos empresarios industriales y agricolas ubicados dentro del sector informal de la economia que no llegaban a ser sujelos de crédito de la Banca Comercial. Eslas tres instiluciones son:

a) La Federación de Cajas de Crédilo (FEDECCREDITO), creada en 1942 en base al segundo inciso del Artículo primero de la Ley de Crédito Rural, el cual literalmente dice: "El sistema será desarrollado por sociedades locales que se denominarán Cajas de Crédito Rural y una Federación de ellas, que coordinará sus lunciones y que se designará Cooperativa de Crédilo Rural Limitada".

b) El Banco de Fomento Agropecuario (BFA), lundado en 1973 como una inslitución descentralizada, mediante el Decreto 312 del 25 de abril de ese año, y destinada a atender financieramente a agricultores de diversos niveles, de preferencia a los pequefios."

c) El Fondo de Financiamiento y Garantía para la Pequeña Empresa (FIGAPE), creado también en 1973.

Ya para 1980 la participación del Eslado se acentúa en la economía y promueve una reorientación del crédito a través de la nacionalización de la Banca, con el propósito de "hacer llegar el crédito primordialmente a la pequena y mediana empresa, lavoreciendo la capacidad empresarial, a través del crédito en función social, y promover el bienestar general de la población y el desarrollo económico y social del pais". ${ }^{10}$

Esto ha sido sustentado en el marco de un Estado participativo y sustentado en "que los criterios (hasta en ese enlonces) aplicados por los bancos y demás instituciones financieras privadas habian ocasionado la concentración del crédito en un pequeño grupo de usuarios, discriminando a aquellos que no han pertenecido a dicho grupo, distorsionando asi las políticas financieras del Estado con proyección social"."

Es así como a partir de 1980, la asistencia crediticia liende a orientarse con un enfoque social, lo que significa que, al menos en parte

8. Régimen Legal de Crédito Rural. Publicación de la Federación de Cajas de Crédito FEDECCREDITO. Pág. 7.

9. Letona, Cruz. "Realidad y perspectivas de la Banca de Fomento Agricola en El Salvador". Cuadernos de investigación. CENITEC, Año II; Mayo 1991. UCA Editores.

10. BFA, Op. Cit.

11. Ley de Nacionalización de las Asociaciones de Ahorro y Préstamo. Decreto No. 58. 
todas las instiluciones pretendian beneficiar con el servicio del crédito primordialmente a la pequena y microempresa y ya no en forma absoluta a la gran empresa.

\subsection{Crecimlento Instliuclonal}

No existe uniformidad sobre el criterio a utilizar para evaluar si una instilución ha crecido o no a nivel general en términos satisfactorios.

Individualmente se suelen considerar el volumen y número de crédilos otorgados, sus costos de operación, las tasas de recuperación y el crecimiento de los principales rubros, entre los que se cuentan los activos, pasivos y patrimonio.

Desde nuestra perspectiva deberá considerarse satisfactorio o aceptable el crecimiento de una inslilución si al comparar su crecimiento patrimonial con el de la economia, medido éste a través del PIB real, el primero es mayor $o$ al menos igual, y complementariamente al interior de cada institución, deben presentarse tasas de crecimiento positivas en cada uno de los rubros principales como: los aclivos, los pasivos y el patrimonio.

\subsubsection{Actlvos Totales}

En relación a los activos tolales de cada una de las instituciones analizadas se observa que han mantenido una tendencia creciente. Sus valores, en miles de colones, han pasado de $\$ 767,675.00$ en 1980 a $\$ 1,618 ; 191.00$ en 1990. Esto nos demuestra que durante el periodo analizado se han duplicado los activos (Ver cuadro 1).

De entre ellas, corresponde la mayor participación al BFA, que reporta un crecimiento del $165 \%$ entre 1980 y 1990; en segundo lugar FE. DECCREDITO, con un crecimienlo de $38.10 \%$ y, al tinal FIGAPE, con $16.70 \%$.

Asimismo, se observa que es partir de 1985 que se opera un alza en la cuantia de los activos tolales para cada inslitución. En el caso de FEDECCREDITO y BFA, es en 1988 el afio en que sus aclivos muestran el punto más alto; por su parte, FIGAPE lo logra en 1985 con $\$ 100,470.00$ miles.

Esle tenómeno se encuentra intimamente relacionado a las modificaciones en las disposiciones puestas en práclica en 1985 sobre el Fondo Operativo, tanto de los Bancos del Sistema Financiero como de las instituciones autónomas (BFA, FIGAPE, FEDECCREDITO).

Dentro de esas disposiciones se encuentran. 


\section{CUADRO 1 \\ La Banca de Fomento en El Salvador 1980 - 1990 \\ Actlvos \\ (Montos en mlles de colones)}

\begin{tabular}{|c|c|c|c|c|c|c|c|c|}
\hline \multirow[t]{2}{*}{ Anos } & \multicolumn{8}{|c|}{ A clivos } \\
\hline & FEDE & $\%$ & B.F.A. & $x$ & FIGAPE & $\mathbf{x}$ & Tolel & $\%$ \\
\hline 1080 & 2201.452 .50 & $0.00 \%$ & $e 506,036.20$ & $0.00 \%$ & 60.186 .30 & $0.00 \%$ & c707,675.00 & $0,00 x$ \\
\hline 1981 & $c 223,548.50$ & $10.97 \%$ & 5590.322 .40 & $16.66 \%$ & $58,203,40$ & $-3.20 \%$ & $2072,074.30$ & $13.60 \%$ \\
\hline 1882 & $c 221,177.80$ & $-1.06 \%$ & 5520.549 .70 & $-10.29 \%$ & c82,655.60 & $7.65 \%$ & ce13.383.40 & $-0.73 \%$ \\
\hline 1803 & $+224,248.80$ & $1.30 \%$ & e $563,054.60$ & $6.33 \%$ & C91,424.10 & 45. $81 \%$ & CB78,728.50 & $0.03 \%$ \\
\hline 1984 & c221,085.00 & $-1.41 \%$ & $6635,545.80$ & $12.87 \%$ & $268,080.60$ & $-3.65 \%$ & $044,721,40$ & $7.51 \%$ \\
\hline 1985 & $c 217,585.90$ & $-1.58 \%$ & c717.083.50 & $12.83 \%$ & $100,470.20$ & $14.05 \%$ & e1.035,138.60 & $0.57 \%$ \\
\hline 1986 & $+275,922.20$ & $20.81 \%$ & $1.044,690.00$ & $45.71 \%$ & $c 70,233.90$ & $-30.09 \%$ & $1,391,052.10$ & $34.38 \%$ \\
\hline \multirow{5}{*}{$\begin{array}{l}1987 \\
1989 \\
1989 \\
1990\end{array}$} & 4279.118 .80 & $1.16 \%$ & C1. $113,718.00$ & $6.59 \%$ & & & $c 1,302,630.80$ & $0.13 \%$ \\
\hline & $c 435.060 .80$ & $55.87 \%$ & e1,214,896.00 & $8.09 \%$ & $c 65,122.20$ & $0.00 \%$ & $(1,715,179.00$ & $23.14 \%$ \\
\hline & $c 280.170 .40$ & $.35 .60 \%$ & $c 1,204,156.00$ & $.0 .68 \%$ & & & $c 1,494,326,40$ & $-13.46 x$ \\
\hline & $c 278,295.70$ & $-0.67 \%$ & $1,339,696.00$ & $11.27 \%$ & & & $61,818,181.70$ & $0.02 \%$ \\
\hline & $22,057,667.40$ & & $c 0,450,254,20$ & & $5866,380.60$ & & $(12,013,300.20$ & \\
\hline
\end{tabular}

Fuente: $\quad$ Memorias de Labores para cada año.

Simbologia:

FEDE. Federación de Cajas de Crédito (FEDECCREDITO)

B.F.A. Banco de Fomento Agropecuario (BFA)

FIGAPE Fondo de Financiamiento y Garantla para la Pequeña Empresa(FIGAPE)

a) Que los bonos del ISTA no se consideren como activos extraordinarios para el cálculo del requerimiento del Fondo Operativo, sino tomo Títulos Valores.

b) Disminuir del $8 \%$ al $6 \%$ lemporalmente el porcentaje del Fondo Operativo del artículo 43 de LICOA.

c) Reducir temporalmenle el porcentaje del Fondo Operativo del $40 \%$ al $20 \%$ según el artículo 43 de LICOA.

Esto con el objelivo de expandir la capacidad de crédito de las instituciones intermediarias, a fin de incrementar la producción.

Hay que recordar que para eslos anos se pone en marcha el Programa de Reactivación Económica en el país.

Esta tendencia es valedera para FEDECCREDITO y BFA, quienes para 1986 muesiran una variación positiva del $26.81 \%$ y $45.71 \%$, respectivamente, siendo para el BFA la mayor de la década; en cambio, FIGAPE registró una disminución del $-30.09 \%$ con respecto al afio anterior. 


\subsubsection{Pasivos Totales}

Por su parte, los pasivos totales muestran un comportamiento claramente definido hacia el alza, ya que pasan a nivel de la Banca de Fomento de $₫ 672,062$ miles en 1980 a $₫ 1,626,734$ miles en 1990 , multiplicándose por 24 los volúmenes de las obligaciones contraídas (Ver cuadro 2).

\section{CUADRO 2 \\ Le Benca de Fomento en El Salvador 1980 - 1990 \\ Pasivos \\ (Montos en miles de colones)}

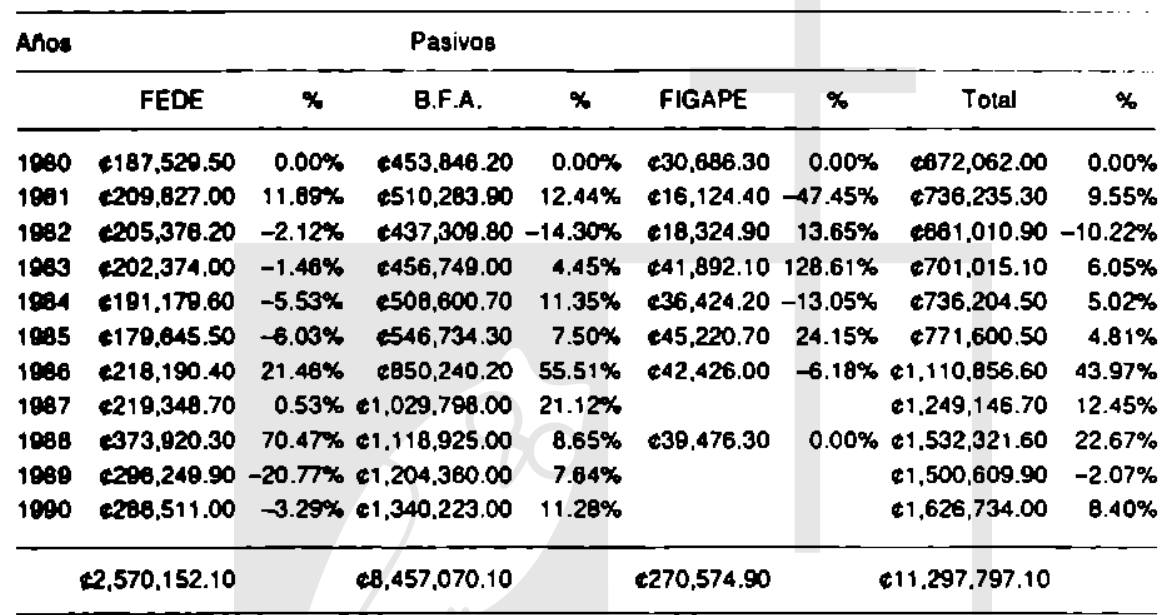

Fuente: Memorias de Labores para cada año.

Hay que hacer observar que los datos del cuadro 2 no incluyen los pasivos tolales de FIGAPE para los años 1989 y 1990, ya que en la actualidad no se encuentran claramente determinada la situación financiera de la institución, prueba de ello es que aún no han sido discutidas, mucho menos presentadas, las respectivas memorias de labores.

En el cuadro 2 podemos observar que a partir de 1985 se da una subida vertiginosa en los pasivos totales de cada una de las instituciones, registrándose para el año de 1986 la variación más alla de la década; una variación que registra un $21.46 \%$ y $55.51 \%$ para FEDECCREDITO y el BFA, respeclivamente; sin embargo, para 1988 FEDECCREDITO alcanza su mayor volumen de pasivos, con $₫ 373,920.30$. Para el caso de FIGAPE, la mayor variación se alcanza en 1983 cuando alcanzó un 
$128.61 \%$ con relación al año anterior.

A nivel global existe una coincidencia entre las dos primeras inslituciones y la Banca de Fomento en general; en lo que respecla a la variación general, se registra la mayor variación anual en los montos de sus pasivos, ya que es para 1986 cuando, a nivel general, se registra la mayor variación, alcanzando el $43.97 \%$ y un valor de $₫ 1,110,856.60$ miles.

\subsubsection{Patrlmonlo}

Dentro del Patrimonio se ha incluido el Capital, Reservas y el correspondiente Superávil o déficit, según el caso, y a lo largo de los anos $\mathbf{8 0}$ existen dos tramos fácilmente identificables y con lendencia contraria.

El primero se ubica en forma ascendente a partir de 1980 con 495 ,612.80 miles hasta 1986 cuando el Patrimonio tolal de la Banca de Fomento alcanza $\$ 280,195.30$ miles (Ver cuadro 3), y el segundo, a partir de este afio y en forma descendente llegando a - $\$ 16,284.30$ en 1989 y $-\varangle 8,542.70$ para 1990.

Esto demuestra la total descapitalización de estas instituciones al final de la década.

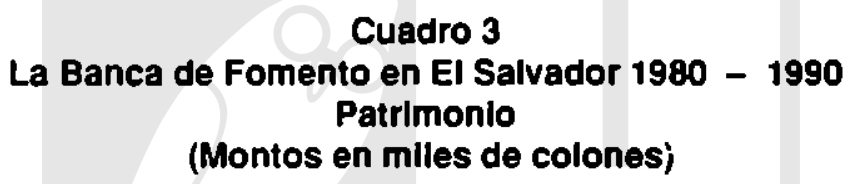

\begin{tabular}{|c|c|c|c|c|c|c|c|c|}
\hline Ano & & & Patrimonio & & & & & \\
\hline & FEDE & * & B.F.A. & $x$ & FIGAPE & $x$ & Tour & $\mathbf{x}$ \\
\hline 1880 & e 13.022 .00 & $0.00 \%$ & $c 52,100 . \infty$ & $0.00 \%$ & 20.500 .00 & $0.00 \%$ & 005.612 .00 & $0.00 \%$ \\
\hline 1981 & c13,721.50 & $-1.45 \%$ & $c 80.039 .50$ & $53.36 x$ & e $42,070.00$ & $42.64 \%$ & e135.800.00 & $42.07 \%$ \\
\hline 1982 & e 15.801 .70 & $15.16 \%$ & $692,242.80$ & $15.25 \%$ & $04,301,00$ & $5.35 \%$ & c152,375,60 & $12.17 \times$ \\
\hline 1983 & $e 37.845 .00$ & $139.51 \%$ & $c 100,305.60$ & $15.25 \times$ & 40.520 .00 & $11.73 \%$ & e193.e83.50 & $27.11 x$ \\
\hline 1084 & $c 20,006,40$ & $-20.98 \%$ & c126,945.10 & $10.42 \times$ & $e 51,666,40$ & $4.31 \%$ & 200.516 .00 & $7.60 \%$ \\
\hline 1985 & c 38.120 .40 & $27.47 \%$ & c170.349.20 & $34.19 \%$ & c55.249.50 & $0.04 \%$ & $2883,718.10$ & $26.47 \%$ \\
\hline 1986 & c57.731.80 & $51.45 \%$ & c194,655.60 & $14.27 \%$ & $c 27.807 .80$ & $-49.67 \%$ & $c 280,185.30$ & $6.25 \%$ \\
\hline 1807 & e59.770.10 & $3.53 \%$ & $c 83.020 .00$ & $-56.69 \%$ & & & C143,600.10 & $-48.72 \%$ \\
\hline 1988 & e61.140.50 & $2.29 \%$ & 696.071 .20 & $14.48 x$ & $25,025,00$ & $0.00 x$ & $c 182,857.60$ & $27.26 \%$ \\
\hline 1080 & $(c 16.079 .60)$ & $-126.30 x$ & $(0-204.70)$ & $-100.21 \%$ & & & $(616,294.30)$ & $-108.01 \%$ \\
\hline \multirow[t]{2}{*}{1000} & $(c 8.215 .30)$ & $-48.01 \%$ & $(c-327.40)$ & $50.04 x$ & & & $(c 8,642.70)$ & $-47.54 x$ \\
\hline & e303.665.30 & & c1.002.188.00 & & $325,811,70$ & & C1,631,683.00 & \\
\hline
\end{tabular}

Fuente: Memorias de Labores para cada año. 
A nivel individual, FEDECCREDITO registra su mayor valor patrimonial en 1988 alcanzando $661,140.5$ miles; por su parte, el BFA lo hace en 1986 cuando tiene registrado $₫ 194,655.60$ miles, y una variación de $14.27 \%$ con respecto al ano anterior.

Igualmente sucede con FIGAPE, que para 1985 registra $\$ 55,249.50$ miles y una variación del $6.94 \%$. Sin embargo, para el ano siguiente (1986), tiene una disminución de $\$ 27,441.60$ miles, 10 que significó una variación negativa del $-49.67 \%$.

Es de hacer nolar que para 1989 y 1990 se obtienen valores negativos, tanto a nivel individual de cada institución, como a nivel de toda la Banca de fomento, llegando a registrarse $-108.91 \%$ y $-47.54 \%$ respectivamente.

Las consideraciones pertinentes se hacen al final del presente capilulo.

\subsection{Indice de crecimiento general}

Tal como se puede apreciar en el cuadro 4, el comportamiento del "Indice de Crecimiento General" (ICG) a lo largo de la década de los anos ochenta ha sido oscilatorio, pero en general tendencialmente superior al crecimiento de la economia, con excepción de los ańos 1982 , 1987 y 1989.

Para 1981, tenemos que la economia (medida a través del Producto Interno Bruto), decreció en un - $8.70 \%$ y que la Banca de Fomento creció en un $13.60 \%$; esto hizo que el crecimiento inslitucional de la Banca de Fomento considerada como un todo, haya superado en un $21.88 \%$ a los primeros, mosirando un crecimiento muy bueno y que fuera el segundo mayor de la década. El primero fue en 1986 con un margen superior en un $34.68 \%$.

Pero para 1982 tenemos que la Banca de Fomento decreció, bajando hasta un $6.73 \%$, porcentaje que, comparado con el crecimiento del PIB que fue del $-5.6 \%$, muesira que el PIB decreció en menor cuantía que la Banca de Fomento (Ver cuadro 4).

A partir de este año, tenemos una recuperación en cada una de las instiluciones consideradas, mostrando en el ICG una tendencia hacia el alza hasta llegar a su punto más alto en 1986, con un crecimiento del $34.38 \%$.

Ya para 1987 y los años subsiguientes, comienza a configurarse una lendencia decreciente, pasando de $0.13 \%$ en 1987 hasla un valor negativo de $-13.46 \%$ en 1989 (Ver cuadro 4). 


\section{Cuadro 4}

La Banca de Fomento en El Salvador 1980 - 1990 indice de crecimiento general

\begin{tabular}{|c|c|c|c|c|c|c|c|c|c|}
\hline \multirow[t]{2}{*}{ Años } & \multicolumn{9}{|c|}{ Indice de crecimiento general } \\
\hline & FEDE & PIB & B.F.A. & PIB & FIGA & PIB & Tolal & $\mathrm{PIB}$ & bifer.. \\
\hline 980 & \multicolumn{2}{|c|}{$0.00 \%(-8.70)$} & $0.00 \%$ & -8.70 & \multicolumn{2}{|c|}{$0.00 \%(-8.70)$} & $0.00 \%$ & -8.70 & 0.1070 \\
\hline 981 & $10.97 \%$ & 8.28 & $16.66 \%$ & 6.28 & $-3.29 \%$ & 6.28 & $13.60 \%$ & -8.28 & $21.80 \%$ \\
\hline 982 & $-1.06 \%$ & 5.60 & $-10.29 \%$ & 5.60 & $7.65 \%$ & 5.60 & $-6.73 \%$ & 5.60 & $-1.13 \%$ \\
\hline 383 & & & & & & & & 90 & \\
\hline 984 & $-1.41 \%$ & 2.27 & 12.87 & 2.27 & $-3.65 \%$ & 2.27 & & 2.27 & 5.24 \\
\hline 985 & $-1.58 \%$ & 1.98 & $12.83 \%$ & 1.98 & $14.05 \%$ & 1.98 & $9.57 \%$ & 1.98 & $7.59 \%$ \\
\hline 986 & $26.81 \%$ & 0.63 & $45.71 \%$ & 0.63 & $-30.09 \%$ & 0.63 & $34.38 \%$ & 0.63 & $33.75 \%$ \\
\hline 1987 & $1.16 \%$ & 2.69 & $6.59 \%$ & 2.69 & $0.00 \%$ & 2.69 & $0.13 \%$ & 2.69 & $-2.56 \%$ \\
\hline 1988 & $55.87 \%$ & 1.63 & $9.09 \%$ & 1.63 & $0.00 \%$ & 1.63 & $23.14 \%$ & 1.63 & $21.51 \%$ \\
\hline 1989 & $-35.60 \%$ & 1.06 & $-0.89 \%$ & 1.06 & $0.00 \%$ & 1.06 & $-13.46 \%$ & 1.06 & $-14.52 \%$ \\
\hline 1990 & $-0.67 \%$ & 3.40 & $11.27 \%$ & 3.40 & $0.00 \%$ & 3.40 & $9.02 \%$ & 3.40 & $5.62 \%$ \\
\hline
\end{tabular}

Fuente: Elaboración propia sobre la base del Cuadro No, 1

Simbología

PIB Tasa de crecimiento del Producto Interno Bruto (PIB) en términos reales

Dileren. Diferencial entre el crecimiento de la Banca de Fomento y el PIB,

Sin embargo, se registra una recuperación para 1990 de $9.02 \%$, producto principalmente de las operaciones realizadas por el BFA que para este año mostró un crecimiento del $11.27 \%$, muy superior al $3.4 \%$ experimentado en la economia.

\subsection{Rentabilldad: gastos versus ingresos de operaclón}

La concesión de créditos en forma segura es importante ya que de ellos depende la recuperación de los coslos de operación en general. Exisle un debate aún no terminado, en torno a si las instituciones como las de fomento deben o no tener tasas subsidiadas en sus operaciones. Tradicionalmente, esto ha sido asi y entre las justilicaciones se encuenIran: los efectos redistribulivos que se pueden lograr y el incenlivo para los usureros del seclor financiero no lormal.

Sin embargo, los datos mostrados por las 3 instituciones en sus estados financieros durante la última década indican que la politica de subsidios no ha sido beneficiosa y no ha reportado los resultados esperados 
que de ella se tenian. En este sentido, es valedera la crítica neoliberal sobre que ha existido una ineliciente asignación de los recursos crediticios, y, por ende, un debilitamiento financiero.

La conclusión bajo nuestro punlo de vista es que la aplicación de lasas de interés reales positivas tienen más probabilidad de alcanzar los efectos esperados en lérminos de equidad, eficiencia y viabilidad de cara a lograr programas de desarrollo en forma autolinanciable, ya que permitirían la recuperación de los costos de operación en general.

Como ya senalamos, un punto de referencia sumamente útil sobre este aspeclo podria constituirlo la tasa de interés pasiva que la Banca Comercial paga por los depositos a 180 días plazo, ya que esta representa el costo de oporlunidad de esos recursos.

Esle no ha sido el caso de la Banca de fomento en El Salvador. Para demostrarlo, se muestran las ganancias obtenidas por las 3 instiluciones durante el período analizado en el cuadro 5, correspondiendo a las ganancias de FEDECCREDITO, BFA, FIGAPE y la Banca de Fomento en general, respectivamenle. En este cuadro se puede observar que la banca de fomento inicia la década con un valor sumamente allo de $₫ 9,777.2$ miles y ya para 1981 se reduce a $₫ 775.2$ miles, variando en un $-92.28 \%$. A partir de este año, existe una recuperación que dura los dos años siguientes, elevándose las ganancias a $₫ 1,808.4$ y $₫ 8,571.9$ miles para 1982 y 1983, respectivamenle.

Para 1984, las ganancias se reducen a $\$ 5,152.4$, y aunque para el año siguiente se logra una recuperación del $29.74 \%$, cuando las ganancias de la Banca de Fomento llegan a $\$ 6,684.5$, exisle una marcada tendencia hacia la baja. En 1986 hay una caída total de las ganancias llegando a registrarse $-\varangle 5,989.1$ miles y una variación del $-189.60 \%$.

Esta caída coincide con el período de alza de los pasivos totales para los anos 1985-1986, perído en que, como se demostró anteriormente, se alcanza la mayor cuanlia en los pasivos totales de la Banca de Fomento.

A nivel individual, FEDECCREDITO muestra el mismo comportamiento para el periodo $1985-86$ ya que pasa de $₫ 4,262.0$ miles a $₫ 607.5$ y $\$ 112.1$ miles, para los anos 1983, 1984 y 1985 respectivamente: Esto significó una variación consecutiva y negaliva de $-85.75 \%$ y $-81.55 \%$ para 1984 y 1985, respeclivamente, con relación al ano anterior.

Por su lado, el BFA muestra un alza en sus ganancias durante el periodo $1980-85$, pasando de $₫ 323.9$ miles en 1980 a $₫ 5,118.3$ en 1985 ; pero a partir de este afio caen a $₫ 590.5, \$ 428.6$ y $₫ 300.0$ en los años 1986, 1987 y 1988, respectivamente. 


\section{Cuadro 5}

La Banca de Fomento en El Salvador 1980 - 1990

Ganancias

(Montos en miles de colones)

\begin{tabular}{|c|c|c|c|c|c|c|c|c|}
\hline \multirow[t]{2}{*}{ Anos } & \multicolumn{8}{|c|}{ Ganancias } \\
\hline & FEDE & * & B.F.A & $\mathbf{x}$ & FIGAPE & $\%$ & Tolal & x \\
\hline 1980 & $c 2.803 .00$ & $0.00 x$ & e323.90 & $0.00 \%$ & 66.650 .30 & $0.00 x$ & $c 9.77720$ & $0.00 x$ \\
\hline 1981 & $c 19.80$ & $-90.28 \%$ & $c 1,787.70$ & $451.93 x$ & $(c 1,052.30)$ & $-115.62 \times$ & c755.20 & $-92.28 \%$ \\
\hline 1802 & $c 615.80$ & $3010.10 \%$ & $e 2,164.80$ & $21.09 \%$ & $(c 972.20)$ & $-7.61 x$ & $c 1.808 .40$ & $130.46 \%$ \\
\hline 1883 & 4.262 .00 & $582.11 \%$ & $e 3.275 .80$ & $51.32 \%$ & $1,034.10$ & $-206.37 \%$ & $c 8.571 .90$ & $374.00 \%$ \\
\hline 1884 & 6607.50 & $-85.75 \%$ & $C 4.887 .20$ & $49.19 \%$ & (e342.30) & $-130.10 \%$ & $c 5.152 .40$ & $-39.89 \%$ \\
\hline 1985 & C112.10 & $-91.55 \%$ & $e 5.118 .30$ & $4.73 \%$ & 1.454 .10 & $-524.80 \%$ & $c 6.684 .50$ & $29.74 \times$ \\
\hline 1986 & c621.20 & $454.15 \%$ & c580.50 & $-89.46 \%$ & $(c 7.200 .80)$ & $-595.21 \%$ & (c5.989.10) & $-189.60 x$ \\
\hline 1987 & $c 54.00$ & $-12.43 \%$ & 2428.60 & $-27.42 \%$ & & & 6972.60 & $-116.24 \%$ \\
\hline 1868 & $(c 634.80)$ & -216.694 & $<300.00$ & $-30.00 \%$ & 66.820 .90 & $0.00 \times$ & e6.586.10 & $577.16 \%$ \\
\hline 1999 & $(c 78.454 .30)$ & $12258.90 \%$ & $(e 300.819 .00)$ & $-100073.00 x$ & & & (c379.273.30) & $-5858.69 x$ \\
\hline 1990 & $(e 21.237 .60)$ & $-72.93 \%$ & $(c 122.714 .00)$ & $-59.21 \%$ & & & (c143.951.60) & $-62.05 \%$ \\
\hline & $(-90.741 .30)$ & & $(C 404,656.20)$ & & $c 6,491,80$ & & $(C 488,005.70)$ & \\
\hline
\end{tabular}

Fuente: Memorias de Labores para cada año,

Ya para 1989 se reportan pérdidas por $₫ 300,819.0$ miles y $\$ 122,-$ 714.0 en los años 1989 y 1990, mostrando una tolal descapilalización y la mala situación financiera en que se encuentran.

En el caso de FIGAPE solo se tienen variaciones negativas y sumamente elevadas, siendo del $-133.10 \%,-52480 \%$ y $-595.21 \%$ para los anos 1984, 1985 y 1986,respectivamente, tal como se muestra en el cuadro 5.

\subsection{Solvencla: Indlce de solvencla patrimonlal}

La solvencia, entendida como la capacidad de una institución para hacer trente a sus obligaciones o pasivos, es vital para su funcionamiento y permanencia a través del tiempo. Con el objeto de mantenerla constante, hemos decidido tomar como referencia el valor estimado en el artículo 40 de la Ley de Bancos y Financieras vigente. En ella se establece que una institución para lograr un nivel satislactorio "debe presentar en todo tiempo una relación de por lo menos el ocho por ciento enlre 
su fondo patrimonial y la suma de sus activos". ${ }^{12}$ Además, se eslablece que "en todo caso, el fondo palrimonial no podrá ser inferior al cuatro por cienlo de sus obligaciones o pasivos totales con lerceros". ${ }^{13}$

Los resultados son mostrados a continuación en el Cuadro 6. Como se podrá observar, cada inslilución muestra en forma singular su situación financiera. Para el caso de FEDECREDITO comienza 1980 con un $6.91 \%$ muy cercano al $8 \%$ que es nuestro parámelro; luego alcanza su mayor índice en 1987 cuando logra subir al $21.41 \%, 13.41$ puntos arriba del valor minimo establecido. Pero a continuación refleja una caida drástica por el valor que va desde $14.05 \%,-5.74 \%$ y $-2.95 \%$ para los años de 1988, 1989 y 1990, respectivamente. Lo mismo sucede con el BFA que comenzando con un $10.31 \%$ en 1980 llega a un $-0.02 \%$ para 1990 .

Hay que recordar que el BFA mantuvo tasas de retorno bajas, pero positivas, y para tinales de la década sus estados financieros reportaron pérdidas de 300 millones de colones. Esto producto de la acumulación

\section{Cuadro 6}

La Banca de Fomento en El Salvador 1980 - 1990 Indice de solvencia patrimonial

(Patrimonio/Aclivos Tolales)

\begin{tabular}{lrrrrrr}
\hline Anos & \multicolumn{3}{c}{ Indice de solvencia patrimonial } & & \\
& FEDE & B.F.A. & FIGAPE & Total & Diferen. \\
\hline 1980 & $6.91 \%$ & $10.31 \%$ & $49.01 \%$ & $12.45 \%$ & $4.45 \%$ \\
1981 & $6.14 \%$ & $13.56 \%$ & $72.30 \%$ & $15.58 \%$ & $7.58 \%$ \\
1982 & $7.14 \%$ & $17.42 \%$ & $70.75 \%$ & $18.73 \%$ & $10.73 \%$ \\
1983 & $16.88 \%$ & $18.88 \%$ & $54.18 \%$ & $22.04 \%$ & $14.04 \%$ \\
1984 & $13.53 \%$ & $19.97 \%$ & $58.65 \%$ & $22.07 \%$ & $14.07 \%$ \\
1985 & $17.52 \%$ & $23.76 \%$ & $54.99 \%$ & $25.48 \%$ & $17.48 \%$ \\
1986 & $20.92 \%$ & $18.63 \%$ & $39.59 \%$ & $20.14 \%$ & $12.14 \%$ \\
1987 & $21.41 \%$ & $7.54 \%$ & $0.00 \%$ & $10.32 \%$ & $2.32 \%$ \\
1988 & $14.05 \%$ & $7.91 \%$ & $39.38 \%$ & $10.66 \%$ & $2.66 \%$ \\
1989 & $-5.74 \%$ & $-0.02 \%$ & $0.00 \%$ & $-1.10 \%$ & $-9.10 \%$ \\
1990 & $-2.95 \%$ & $-0.02 \%$ & $0.00 \%$ & $-0.53 \%$ & $-8.53 \%$ \\
\hline
\end{tabular}

12. Ley de Bancos y Financieras, República de El Salvador. Capltulo V. "Relación entre Fondo Patrimonial y Activos Ponderados". Página 7, literal a). 13. Ibid. 
en sus activos de crédilos lotalmente irrecuperables. En el caso de FIGAPE, solamente se tienen registros hasta el afo de 1986, y sus indices van del $49.01 \%$ en 1980 al $39.38 \%$ en 1988 .

En lorma general la Banca de Fomento en su conjunto muestra un ascenso a partir de 1980 , pasando de $12.45 \%$ en 1980 a $25.48 \%$ en 1985, para luego caer a un $-1.10 \%$ y $-0.53 \%$ en los años 1989 y 1990 , respectivamente. En este período hay que recordar que se tuvieron los efeclos del lerremoto de 1986, que influyeron negativamente en el ámbiIo nacional.

\subsection{Cuantlflcación de las operaclones reallzadas en el área cre- dilicia}

\subsubsection{Por montos de crédito}

De 1980 a 1990 , se tiene que FEDECCREDITO ha otorgado un total de $₫ 1,244,701.8$ miles; el BFA $₫ 4,738,056.0$ miles y FIGAPE $₫ 112$, 209.30 miles. En total las 3 instituciones han olorgado $₫ 6,094,967.1 \mathrm{mi}$ les de colones en conceplo de crédito para el periodo en cuestión (Ver cuadro 7).

Como se puede observar, la participación de cada una de las insliluciones en el olorgamiento del crédito varia; y porcentualmente se liene para el BFA el $77.74 \%$; para FEDECCREDITO el $20.24 \%$, y para FIGAPE el $1.84 \%$, del total. Esto sitúa en el primer lugar al BFA con el $75 \%$ del tolal de monlos olorgados en el década de los años 80 , superando ampliamente a las otras insliluciones.

Globalmente, podemos observar que ha existido una tendencia creciente en el total de montos otorgados, ya que se han duplicado en la década, pasando de $\$ 405,558.7$ miles en 1980 a $\$ 859,141$ miles en 1990. Esto demuestra que al menos en base a los montos de crédito olorgados si se ha alcanzado conceder mayor cantidad de créditos.

\subsubsection{Por el número de usuarlos}

El segundo parámetro para medir el grado de electividad que ha tenido la Banca de Fomenlo en nuestro pais es la cuantificación del número de personas que han tenido créditos en cada una de las instituciones. En tal senlido, podemos considerar que entre mayor sea el número de beneficiarios directos, mayor ha sido la profundización dentro de un proceso de democratización del crédito.

Sobre esta base se han registrado la cantidad de usuarios del crédito en eslas tres instituciones a lo largo de la década de los anos 80 's. Hay 


\section{Cuadro 7 \\ La Banca de Fomento en El Salvador 1980 - 199 \\ Monto de crédllo \\ (Montos en miles de colones)}

\begin{tabular}{|c|c|c|c|c|c|c|c|c|}
\hline \multirow[t]{2}{*}{ Anco } & \multicolumn{8}{|c|}{ Monies de crédito } \\
\hline & FEDE & $\mathbf{x}$ & B.F.A & $\%$ & FIGAPE & $x$ & Tolal & $x$ \\
\hline 1980 & 498.660 .70 & $0.00 \%$ & $=301,261,00$ & $0.00 \%$ & $t 5.637 .00$ & $0.00 \%$ & C405.558.70 & $0.00 \%$ \\
\hline 1981 & $\$ 90.748 .60$ & $-8.02 \%$ & $c 252,084,00$ & $-16.32 \%$ & $\$ 4,669.00$ & $-17.17 \%$ & $e 347.501 .60$ & $-14,32 \%$ \\
\hline 882 & c74.824.70 & $-17.55 \%$ & $<210,851.00$ & $-16.36 \%$ & $c 8,655.50$ & $42.55 \%$ & c292,331.20 & $\cdot 15,88 \%$ \\
\hline 1983 & $e 63.939 .50$ & $-14.55 \%$ & $<336,500.00$ & $59.59 \%$ & $c 9,485.30$ & $42.49 \%$ & $0409,022.80$ & $40.23 \%$ \\
\hline 1984 & -75.497 .00 & $18.08 \%$ & es 19,800.00 & $24.75 \%$ & $e 9,035.70$ & $-4.72 \%$ & 4504.332 .70 & $23.03 \%$ \\
\hline 1985 & c98.930.50 & $31.04 \%$ & $c 360,000.00$ & $-14.05 \%$ & c $13,528,40$ & $49.72 \%$ & 0473.261 .90 & $-6.16 \%$ \\
\hline 1986 & $c 140.474 .10$ & $41.99 \%$ & $e 567,700.00$ & $57.34 \%$ & c 19.414 .90 & $43.51 \%$ & c727,589.00 & $53.74 \%$ \\
\hline 1987 & c $141,300.00$ & $0.59 \%$ & $e 555,000.00$ & $-2.24 \%$ & $c 26.305 .20$ & $35.49 \%$ & c722.605.20 & $-0.68 \%$ \\
\hline 1988 & c $129,829.60$ & $-8.05 \%$ & C441, 100.00 & $-20.52 \%$ & $e 17.460 .30$ & $0.00 \%$ & c589,509.90 & $-18.56 \%$ \\
\hline 1989 & c $125,213.10$ & $-3.63 \%$ & $e 639,000.00$ & $44.87 \%$ & & & $c 764,213.10$ & $29.86 \%$ \\
\hline 1990 & e205.181.00 & $63.87 \%$ & $2653,960.00$ & $2.34 x$ & & & $e 859,141.00$ & $12.42 \times$ \\
\hline & $1,244.701 .80$ & & $c 4,738,056.00$ & & 112.209 .30 & & 6.094 .967 .10 & \\
\hline
\end{tabular}

Fuente: Memorias de Labores para cada año.

que mencionar que para evitar la duplicidad de datos, se han tomado como base para nuestro registro el número de usuarios directos y no el número de créditos otorgados, ya que puede darse el caso que una misma persona haya podido contralar más de un crédito para dislintos deslinos.

La tendencia mostrada por el número de usuarios direclos del crédito muestra un alza moderada a lo largo de los anos 80 . El movimiento se inicia en 1980 con 69,731 créditos otorgados a igual número de usuarios directos, manteniéndose casi inalterada la cuantia, hasta 1984, ano en que se observa su punto más bajo con 67,715 usuarios. Luego se registra una recuperación del $82.75 \%$ a partir de 1985 , alcanzando la segunda mayor cilra, cantidad que asciende a 123,628 usuarios (Cuadro 8). Esla recuperación es continuada hasla, 1986 ya que en éste se alcanza la mayor cantidad de usuarios y cuyo lolal asciende a 186,886.

A partir de este afio si bien es cierto las cantidades en cuanto al otorgamienlo de créditos es considerable, muestran su segunda fase de decrecimiento, disminuyendo el número de usuarios direclos en $25.09 \%,-12.20 \%,-0.72 \%$ y $-2.98 \%$ para los ahos 1987,1989 y 1990 , 
Cuadro 8

La Banca de Fomento en El Salvador 1980 - 1990 Número de usuarlos del credito

\begin{tabular}{|c|c|c|c|c|c|c|c|c|}
\hline \multirow[t]{2}{*}{ Años } & \multicolumn{4}{|c|}{ Número de usuarios del crédito } & \multirow[b]{2}{*}{ FIGAPE } & \multirow[b]{2}{*}{$\%$} & \multirow[b]{2}{*}{ TOTAL } & \multirow[b]{2}{*}{$\%$} \\
\hline & FEDE & $\%$ & $B, F, A$, & $\%$ & & & & \\
\hline 1980 & 20,868 & $0.00 \%$ & 48,464 & $0.00 \%$ & 399 & $0.00 \%$ & 69.731 & $0.00 \%$ \\
\hline 1981 & 28,101 & $34.66 \%$ & 45,866 & $-5.36 \%$ & 455 & $14.04 \%$ & 74,422 & $6.73 \%$ \\
\hline 1982 & 23,694 & $-15.68 \%$ & 50,522 & $10.15 \%$ & 542 & $19.12 \%$ & 74,758 & $0.45 \%$ \\
\hline 1983 & 24,374 & $2.87 \%$ & 47.658 & $-5.67 \%$ & 755 & $39.30 \%$ & 72,787 & $-2.64 \%$ \\
\hline 1984 & 22,320 & $-8.43 \%$ & 44,588 & $-6.44 \%$ & 807 & $6.89 \%$ & 67.715 & $-6.97 \%$ \\
\hline 1985 & 69,159 & $209.85 \%$ & 52,988 & $18.84 \%$ & 1,481 & $83.52 \%$ & 123,628 & $82.57 \%$ \\
\hline 1986 & 125,530 & $81.51 \%$ & 58,507 & $10.42 \%$ & 2,849 & $92.37 \%$ & 186.806 & $51.17 \%$ \\
\hline 1987 & 88,650 & $-29.38 \%$ & 46,126 & $-21.16 \%$ & 5,228 & $83.50 \%$ & 140,004 & $-25.09 \%$ \\
\hline 1988 & 77,530 & $-12.54 \%$ & 42,427 & $-8.02 \%$ & 2,962 & $0.00 \%$ & 122,919 & $-12.20 \%$ \\
\hline 1989 & 75.114 & $-3.12 \%$ & 46,915 & $10.58 \%$ & & & 122,029 & $-0.72 \%$ \\
\hline \multirow[t]{2}{*}{1990} & 85,844 & $14.28 \%$ & 32,546 & $-30.63 \%$ & & & 118,390 & $-2.98 \%$ \\
\hline & 641,184 & & 516,607 & & 15,478 & & $1,173,269$ & \\
\hline
\end{tabular}

Fuente: Memorias de Labores para cada año.

respectivamente (Cuadro 8 ).

Globalmente, se han dado $1,173,269$ créditos, de los cuales el $54.65 \%$ ha sido proveído por FEDECCREDITO; el $44.03 \%$ por el BFA y el restante $1.05 \%$ por FIGAPE. Un dato llamativo es el caso de FIGAPE que para 1987 alcanza un total de 5,228 créditos olorgados, cantidad que supera en un $83.5 \%$ al ano anterior y en un $1210 \%$ el ano base (1980). Esto puede ser explicado diciendo que desde su creación en 1973 hasta 1984, la instilución operaba con una estructura administrativa centralizada, integrada por la oficina central en San Salvador, dos agencias más, una en Sanla Ana y otra en San Miguel y una corresponsalía en Sonsonale. Pero a partir de 1984 se da una reestructuración con miras expansionistas y para ello descentralizan las operaciones mediante la creación de nuevas agencias, la creación de Corporaclones de Desarrollo, los Centros de Acopio y la formación de empresas. Esto tuvo como resultado el aumenlo de las agencias en todo el pais, llegando a tolalizar 22 y ello implica, consecuentemente, la cobertura de su área crediticia. 


\subsubsection{Por el número de beneflclarlos directos y el número de no benellclados}

En el cuadro 9 se presenta el número de beneficiaros directos logrados sobre la base de la concesión de créditos durante la década de los 80. Como se observa, a lo largo de la década se han beneficiado individualmente a 1,446,306 personas, de las cuales 914,221 lo han sido por parte de FEDECCREDITO (63.21\%); 516,607 por el BFA $(35.72 \%) y$, 15,478 por FIGAPE (1.07\%).

\section{Cuadro 9}

La Banca de Fomento en El Salvador 1980 - 1990 Número de beneflclarios directos de la concesión del crédito

\begin{tabular}{|c|c|c|c|c|c|c|c|c|}
\hline \multirow[t]{2}{*}{ Alos } & \multicolumn{8}{|c|}{ Número de beneficierios directos de la concesión del crédito } \\
\hline & FEDE & $\%$ & B.F.A, & $\%$ & FIGAPE & $\%$ & Total & $\%$ \\
\hline 1880 & 68,347 & $0.00 \%$ & 48,464 & $0.00 \%$ & 399 & $0.00 \%$ & 117,210 & $0.00 \%$ \\
\hline 1891 & 71,380 & $4.44 \%$ & 45,866 & $-5.36 \%$ & 455 & $14.04 \%$ & 117,701 & $0.42 \%$ \\
\hline 1892 & 75,283 & $5.47 \%$ & 50,522 & $10.15 \%$ & 542 & $19.12 \%$ & 126,347 & $7.35 \%$ \\
\hline 1983 & 78,604 & $4.41 \%$ & 47,658 & $-5.67 \%$ & 755 & $39.30 \%$ & 127.017 & $0.53 \%$ \\
\hline 1984 & 82,431 & $4.87 \%$ & 44,588 & $-6,44 \%$ & 807 & $6.89 \%$ & 127.826 & $0.64 \%$ \\
\hline 1985 & 86,435 & $4.86 \%$ & 52,988 & $18.84 \%$ & 1,481 & $83.52 \%$ & 140,904 & $10.23 \%$ \\
\hline 1886 & $\theta 7,149$ & $12.40 \%$ & 58,507 & $10.42 \%$ & 2,849 & $92.37 \%$ & 158,505 & $12.49 \%$ \\
\hline 1887 & 94,249 & $-2.99 \%$ & 46,126 & $-21.16 \%$ & 5,228 & $83.50 \%$ & 145,603 & $-8.14 \%$ \\
\hline 1888 & 84,015 & $-10.86 \%$ & 42,427 & $-8.02 \%$ & 2,962 & $0.00 \%$ & 129.404 & $-11.13 \%$ \\
\hline \multirow{3}{*}{$\begin{array}{l}1899 \\
1990\end{array}$} & 81,397 & $-3.12 \%$ & 46,915 & $10.58 \%$ & & & 128,312 & $-0.84 \%$ \\
\hline & 94,031 & $16,63 \%$ & 32,546 & $-30,63 \%$ & & & 127,477 & $-0,65 \%$ \\
\hline & 914,221 & & 516,607 & & 15,478 & & $1,446,306$ & \\
\hline
\end{tabular}

Fuente: Memorias de Labores para cada año,

Nota: Para el número de benericiarios de FEDECCREDITO se tomo como base el número de afiliados en cada una de las Cooperativas.

Esta cantidad puede parecer sumamente elevada, pero habria que considerar si ha sido suliciente para satislacer a todos o a la mayor parte de los demandantes y que, si lo es, qué proporción de ellos constituye la cuantla satisfecha e insatisfecha.

En el cuadro 10 se muestra esta información. En él se ha contemplado la población económicamenle activa (PEA) y se conlrasta con el número de beneficiarios directos, oblenido en el Cuadro 9. Como se puede apreciar, la PEA para 1990 ascendió a 1,825,531 habitantes, proyectada con un incremento anual del $3.39 \%$ a partir de 1986 . De esta población, 127,477 fueron beneficiados con la concesión de créditos, representan- 
do ello el $6.98 \%$ del total, pero dejando desprovisto de ellos al $93.02 \%$ resiante.

\section{Cuadro 10}

La Banca de Fomento en El Salvador 1980 - 1990 Cantldad de beneficlados y no beneficlados

\begin{tabular}{|c|c|c|c|c|c|c|}
\hline \multirow[t]{2}{*}{ Años } & \multicolumn{4}{|c|}{ Cantidad de beneliciados por año } & \multirow[b]{2}{*}{ No. Benefic. } & \multirow[b]{2}{*}{$\%$} \\
\hline & PEA & $\%$ & Benetic. & $\%$ & & \\
\hline 1980 & $1,113,590$ & $100.00 \%$ & 117,210 & $10.53 \%$ & 996,380 & $89.47 \%$ \\
\hline 1981 & $1,461,632$ & $100.00 \%$ & 117,701 & $8.05 \%$ & $1,343,931$ & $91.95 \%$ \\
\hline 1982 & $1,466,765$ & $100.00 \%$ & 126,347 & $8.61 \%$ & $1,340,418$ & $91.39 \%$ \\
\hline 1983 & $1,471,440$ & $100.00 \%$ & 127,017 & $8.63 \%$ & $1,344,423$ & $91.37 \%$ \\
\hline 1984 & $1,494,504$ & $100.00 \%$ & 127,826 & $8.55 \%$ & $1,366,678$ & $91.45 \%$ \\
\hline 1985 & $1,545,205$ & $100.00 \%$ & 140,904 & $9.12 \%$ & $1,404,301$ & $90.88 \%$ \\
\hline 1986 & $1,597,626$ & $100.00 \%$ & 158,505 & $9.92 \%$ & $1,439,121$ & $90.08 \%$ \\
\hline 1987 & $1,651,785$ & $100.00 \%$ & 145,603 & $8.81 \%$ & $1,506,182$ & $91.19 \%$ \\
\hline 1988 & $1,707,781$ & $100.00 \%$ & 129,404 & $7.58 \%$ & $1,578,377$ & $92.42 \%$ \\
\hline 1989 & $1,765,674$ & $100.00 \%$ & 128,312 & $7.27 \%$ & $1,637,362$ & $92.73 \%$ \\
\hline 1990 & $1,825,531$ & $100.00 \%$ & 127,477 & $6.98 \%$ & $1,698,054$ & $93.02 \%$ \\
\hline & $17,101,533$ & & 140 & & $15,655,227$ & \\
\hline
\end{tabular}

Fuente: Diagnóstico Social: Siluación aclual de las necesidades básicas en EI Salvador, FUSADES, Deplo. de Estudios Económicos y Sociales. Dic. 1986, Pág. 6.

Nota: A partir de 1986 el incremento de la PEA se proyecta con un $3.39 \%$ anual.

Sobre esla cuantia habria que anadir que lo más probable es que ellos lampoco han sido beneficiados por la Banca Comercial, ya que no cumplen los requisitos exigidos por ésla para ser considerados como sujelos de crédito, y que, en tal sentido, han tenido que recurrir en mayor o menor grado al mercado informal de financiamiento.

Asimismo, habria que decir que solamente se han considerado los beneficiarios directos porque sólo ellos, al menos juridicamente, son capaces de contraer un crédilo.

Por otra parte, si bien es cierto que a partir de 1984 los bancos comerciales han alendido a la microempresa, sólo lo han hecho en un promedio del $1.99 \%$ del total de la colocación de fondos (Ver cuadro 11), mientras que en contraposición; el $76.65 \%$ lo ha sido para la gran empresa. 
Esto evidencia que un proceso de democratización del crédito dista mucho de las acciones concrelas y reales llevadas a cabo por estas instiluciones.

\section{Cuadro 11}

Composiclón porcenlual de la distribuclón del crédito por parte de la banca comerclal en EI Salvador

\begin{tabular}{lrrrrrrr}
\hline Tamaños & 1984 & 1985 & 1986 & 1987 & 1988 & 1989 & Media \\
\hline Micro empresa & $2.00 \%$ & $2.00 \%$ & $2.00 \%$ & $2.00 \%$ & $1.98 \%$ & $1.96 \%$ & $1.99 \%$ \\
Pequeña emp. & $14.30 \%$ & $13.00 \%$ & $12.60 \%$ & $14.60 \%$ & $13.42 \%$ & $11.47 \%$ & $13.23 \%$ \\
Mediana & $\mathbf{8 . 5 0 \%}$ & $8.70 \%$ & $7.60 \%$ & $8.10 \%$ & $7.72 \%$ & $8.26 \%$ & $8.15 \%$ \\
Grande & $75.20 \%$ & $76.30 \%$ & $77.80 \%$ & $75.30 \%$ & $76.88 \%$ & $78.31 \%$ & $76.63 \%$ \\
& $100.00 \%$ & $100.00 \%$ & $100.00 \%$ & $100.00 \%$ & $100.00 \%$ & $100.00 \%$ & $100.00 \%$ \\
\hline
\end{tabular}

Fuente: Memoria del Banco Central de Reserva, varios años.

\subsection{Parlicipaclón de la Banca de Fomento en el financlamiento glo- bal de la economia}

Finalmente, tenemos que en forma global la Banca de Fomento cubre parte de la demanda potencial de crédito de la economía salvadorena. La otra parte es satisfecha por los bancos comerciales.

Es de esperarse que la unión de estos dos seclores abarque la casi tolalidad de la demanda de crédito. Por ello queremos presentar el porcentaje de participación que cada sector tiene como parte del sistema financiero del pais.

Tal como se muesira en el Cuadro 12, a lo largo de la década de los 80 la mayor participación ha correspondido lógicamenle a los bancos comerciales. Sin embargo, la Banca de Fomento lambién ha hecho lo suyo, y para 1980 se contaba con $₫ 405,558.7$ miles, lo que representó el $17.07 \%$ en el tinanciamiento global. Este ha sido el ano de mayor participación.

Si se observa, se verá que ha existido una tendencia ascendente en el olorgamiento, en lo que a montos se refiere. Sin embargo, el porcenlaje de participación en el financiamiento total de la economia ha sido descendente, pues ha pasado de un $17.07 \%$ en 1980 a un $6.63 \%$ en 1990.

Ha habido efectivamente una recuperación muy leve de tres puntos en los años de 1986 y 1987; cuando se pasó de un 6.88\% (1985) a 
9.33\%. Esto podria ser el efeclo del programa de reactivación y eslabilización económica puesto en marcha por la administración del ing. Duarte, ya que hay que recordar que estas instiluciones aunque autonomas, responden en general a la política gubernamental.

A continuación, lenemos nuevamente una caída en los anos subsiguientes que va desde $6.69 \%$ en 1988 al $6.63 \%$ en el 89 . Entre los factores explicativos de este nuevo descenso se encuentra el terremoto de 1986 y la profundización de la guerra.

En promedio, a lo largo de la década de los anos 80 las instituciones de fomento han participado en un $10.3 \%$, como se aprecia en los dalos del cuadro 12.

\section{Cuadro 12}

La Banca de Fomento en El Salvador 1980 - 1990 Particlpación de la banca de fomento en el financlamlento

\begin{tabular}{|c|c|c|c|c|c|c|c|}
\hline Anos & $\mathrm{BCH}$ & FEDEC & B.F.A. & FIGAPE & Sub-tal & $\begin{array}{l}\text { Tolal } \\
\text { General }\end{array}$ & $\begin{array}{c}\text { \% Part. } \\
\text { Ba. } \\
\text { Fomento }\end{array}$ \\
\hline $\begin{array}{l}1980 \\
1981 \\
1982 \\
1983 \\
1984 \\
1985 \\
1986 \\
1987 \\
1988 \\
1980 \\
1990\end{array}$ & 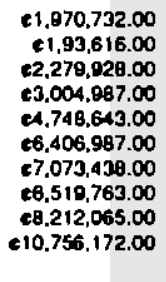 & $\begin{array}{l}c 98,660.70 \\
c 90,748.60 \\
c 74,824.70 \\
c 63,939.50 \\
c 75,497.00 \\
c 99,933.50 \\
\epsilon 140,474.10 \\
c 141,300.00 \\
c 109,029.60 \\
c 125,213.10 \\
c 205,181.00\end{array}$ & $\begin{array}{l}c 301.261 .00 \\
c 252.094 .00 \\
\epsilon 210.851 .00 \\
c 336,500.00 \\
e 410.800 .00 \\
\epsilon 360,800.00 \\
\epsilon 567.700 .00 \\
c 555,000.00 \\
c 441,100.00 \\
c 639,000.00 \\
c 653,960.00\end{array}$ & $\begin{array}{r}c 5.637 .00 \\
e 4,669.00 \\
e 6,655.50 \\
e 8,483.30 \\
e 9,035.70 \\
e 13.528 .40 \\
c 19,414.90 \\
c 26,305.20 \\
c 17,480.30\end{array}$ & $\begin{array}{l}c 405.558 .70 \\
c 347.501 .60 \\
c 202.331 .20 \\
e 409.922 .80 \\
e 504.332 .70 \\
c 473.261 .80 \\
c 727.589 .00 \\
e 722.605 .20 \\
e 568.509 .90 \\
e 764.213 .10 \\
e 859.141 .00\end{array}$ & $\begin{array}{r}c 2,376,290.70 \\
e 2,279,117.60 \\
e 2.572 .259 .20 \\
e 3,414.809 .80 \\
e 5,252,975.70 \\
e 6,880,248.90 \\
e 7,801,027.00 \\
\epsilon 7,242,368.20 \\
e 8,780,574.90 \\
e 11,520.385 .10 \\
c 859,141.00\end{array}$ & $\begin{array}{r}17.07 \% \\
15.25 \% \\
11.36 \% \\
12.00 \% \\
9.80 \% \\
6.69 \% \\
9.33 \% \\
9.99 \% \\
6.47 \% \\
6.63 \% \\
100.00 \%\end{array}$ \\
\hline & $c 52,004,331.00$ & C1,224,701.80 & $c 4.738 .056 .00$ & e1 12,209.30 & $66.074,967.10$ & $c 58,978,28 B .10$ & $10.30 \%$ \\
\hline
\end{tabular}

\subsection{Conclusiones}

Después de realizar el diagnóstico sobre lo que ha sido la gestión de las instituciones FEDECCREDITO, BFA y FIGAPE a lo largo de la década de 1980, se puede concluir que los resultados oblenidos en el cumplimiento de los objetivos de desarrollo han respondido en cierta medida, pero esto les ha signilicado encontrarse descapitalizadas al final del periodo, producto de los allos costos de operación en que incurrieron.

En el área social, la concesión de préslamos efectivamente se duplicó durante la década, pasando de $₫ 405,558.7$ miles en 1980 a $₫ 859,141$ miles en 1990. Esto también fue reflejado en la tendencia hacia el alza en la cantidad de los usuarios del crédito ya que para 1980 se tenían 
69,731 crédilos olorgados y, para finalizar el periodo, 118,380 , registrándose un aumento de casi el doble.

Sin embargo, aunque en forma global se otorgaron $1,437,110$ créditos proveidos en su mayoria por FEDECREDITO $(54.66 \%)$, esto no fue suficiente para cubrir la demanda polencial existente. Esta cuantía sólo alcanzó una coberlura del $6.98 \%$ de la PEA de 1990 ; dejando desprovis10 de esle recurso a $1,698,054$ personas, las que representaron el $93.02 \%$ para el final del periodo (Ver cuadro 13 ).

Podría pensarse que estas personas recurrieron a la banca comercial para financiar sus actividades. Sin embargo, en este punto hay que recordar que ellos no califican como sujelos de crédito y, por to tanto, aunque algunos hubieran obtenido crédito, ello sólo representaría una minima parte.

En este sentido, los efectos positivos logrados en el área social han sido anulados por la mala siluación financiera en que han caido, dando pie a las crílicas neoliberales en cuanto a que su desempeno no ha sido eficiente. Estas criticas deben ser lomadas en cuenta y sobre la participación activa y direcla del Estado relormular una nueva estralegia de acción para cada una de las instiluciones y de la Banca de Fomento en general.

\section{Evaluaclón de modalidades alternativas para lograr un proceso de democrallzación del crélito en EI Salvador}

\subsection{Allernativas}

Las alternativas aqui planleadas tienen como premisa fundamental el saneamiento de cada una de las carteras de estas instituciones, ya que no es posible lograr una reorientación en su funcionamiento cargando con crédilos irrecuperables que sólo representan estados financieros irreales, asi como tampoco se puede lograr si se sigue operando de igual forma como hasla hoy se ha hecho.

Adicionalmenle, se presentan también dos estrategias fundamentales, que pueden ser combinadas con cualquiera de las tres allernativas propuestas para conformar un modelo más complelo y operativo.

\subsubsection{Primera Alternallva: Fuslón de las Instltuciones para formar una Banca de Fomento especiallzada en la atenclón de los micro y pequenos empresarios}

Esta allernativa plantea la creación de una Banca de Fomento a partir de la fusión de las tres instituciones aqui analizadas, especializán- 
dose en la atención de los micro y pequeños empresarios. Al interior de ella existirian Divisiones, deslinadas a asistir con recursos crediticios, capacilación y asesoría en general a cada uno de los seclores que actualmenle son alendidos por cada institución y, adicionalmenle, el resto de microempresarios que aún no han sido atendidos.

Habrán tantas Divisiones como sectores estratégicos hubiesen dentro del sector y con ello se lograria la centralización de funciones, se optimizaria el uso de los recursos existentes tanto financieros como materiales y no habria necesidad de efectuar nuevos gaslos en iniraesiructura, mobiliario y equipo, pues ya se cuenta con él.

Por otra parle esta nueva Banca de Fomenlo no tendría contacto directo con el público, a través de la captación de depósitos. Esto racilitaría su funcionamiento, ya que no tendría necesidad de competir con la Banca Comercial para aumentar sus fuentes de financiamiento.

A nivel interno, deberá apegarse a los parámetros claves establecidos en el modelo de la Banca de Fomento inicialmenle planteados:

a) Lograr una tasa de crecimiento mayor o al menos igual al crecimiento de la economía, medido ésle a Iravés del PIB real,; que refleje el aumento del empleo, la producción, el ingreso y el bienestar en general de sus usuarios, produclo lodo ello de un proceso de democratización del crédilo.

b) Lograr un nivel de rentabilidad tal que, de hecho, logre cubrir sus coslos de operación, y cuyo costo de oporlunidad sea considerado a partir de la lasa pasiva pagada por la Banca Comercial por los depósilos a 180 dias plazo.

c) Mantener un nivel de solvencia adecuado, enlendiéndose por adecuado una relación del $8 \%$ entre su Fondo Palrimonial y el total de sus Aclivos.

d) Absorber un número de usuarios que justitique su existencia como Banca de Fomento de acuerdo a la estrategia adoptada.

\subsubsection{Segunda Alternatlva: Fusión de las instituclones para lormar una Banca de Fomento Mullisectorlal}

Esta allernativa plantea siempre la creación de una Banca de Fomento a partir de la fusión de las tres instituciones, pero ya no en forma especializada, sino multisectorial. Esto signilica que puede adoplar un esquema de Banca Comercial, siempre desempenando su función de intermediación linanciera, pero orientado preferentemente hacia los micro y pequenos empresarios. Con esto se lograría siempre la centraliza- 
ción de los esiuerzos y decisiones y se convertiria en un contrapeso de la Banca estriclamente comercial, pues lendria como opción preferente a los micro y pequeńos empresarios.

En este sentido, seria necesario también captar fondos del público para procurarse fuenles de financiamiento y colocarlos luego en forma de crédito, por lo que las fuentes incluirian ahora a lodos los sectores (de ahi su nombre) y al público en general. Sin embargo, dentro de esta alternaliva existe mayor posibilidad de que se llegue a convertir en una Banca con lógica eminentemente lucrativa, ya que deberá asumir los riesgos que como Banca Comercial deberá tener en cuenta y, en este sentido, el grado de atención a los micro y pequefos empresarios se reduciria, aún siendo su opción preferencial, prolongándose la situación aclual.

Esto limilaria el progreso y velocidad de un proceso de democralización del crédilo y minimizaría el impaclo y la cobertura hacia los microempresarios.

A nivel interno, se tendrian adminisIrativamente Gerencias, entre las que se pueden mencionar: la Gerencia de Créditos, la Gerencia Administrativa, la Gerencia Comercial, etc., dependiendo de la estructura organizaliva que se adople.

Sus fuentes de recursos incluirian a lodos los sectores de la economía nacional, teniendo al Estado siempre como respaldo y ente participativo, los usuarios propios y las donaciones. En este sentido, la cartera sería diversilicada y siempre regida por los parámetros claves establecidos para la primera alternaliva.

\subsubsection{Tercera Alternativa: Creación de una Banca de Fomento de Segundo Plso}

Esta tercera allernativa plantea la creación de una Banca de Fomento siempre a partir de la fusión de las tres instituciones, pero como Banca de Segundo Piso, que se encargarla de olrecer financiamiento y asistencia en general a los micro y pequenos empresarios.

El aspeclo distintivo de esla allernativa sería, primero, que no tendría contacto con el público a través de la captación de depósitos y, en segundo lugar, la asistencia y financiamiento lo llevaria a cabo a través de terceros, entre los que podrlan enconirarse: los bancos comerciales, las Asociaciones de Ahorro y Préstamo, Bancos Comunales, Cooperativas, etc.

A nivel interno, puede estar estructurada por Divisiones o Gerencias, dependiendo de la forma organizativa más adecuada a sus objetivos. 
Las fuentes de sus recursos contemplaría al Estado en primer orden, los recursos propios producto de sus operaciones en el quehacer tinanciero $y$. por último, las donaciones de organismos tanto nacionales como internacionales.

Los usos estarían orientados exclusivamente a los micro y pequefios empresarios, mediante la concesión de créditos y asistencia en general.

Dado que se especializaría en la alención de los micro y pequeños empresarios el impacto y la cobertura seria mayor en el sentido de que pueden ser utilizados los recursos y la infraestructura de todas las instituciones intermediarias para atender al mayor número de usuarios. En este sentido, las perspectivas de lograr un proceso de democralización del crédito son amplias y los riesgos podrian ser distribuidos enlre todos los involucrados.

Sin embargo, creemos que siempre debe ajustarse a los parámetros claves del modelo aqui planteado, para asegurar su crecimiento, la rentabilidad de sus operaciones, la solvencia y el impacto sobre su población objelivo.

\subsection{Estrateglas de desarrollo}

Cualquiera que sea la alternativa elegida para lograr un proceso de democratización del crédito, creemos debe ir acompañada de una estralegia que, en forma complementaria, proporcione un modelo más sólido para lograr esa democratización. Para ello se presentan a continuación dos estrategias que pueden ser implementadas en cualquiera de las allernativas elegidas.

\subsubsection{Primera Estrategla: Absorber el mayor número de micro y pequenos empresarlos dotándoles de capltal y asistencla en general con crecimiento Instituclonal.}

Esta primera estrategia planlea lograr absorber una cantidad determinada de micro y pequenos empresarios por ano, dolándoles de recursos crediticios, medios y canales de comercialización adecuados, capacilación en general y asesoría técnica. Después de ello se espera que en forma individual o asociados, cada microempresario sea capaz de: competir en el mercado nacional con sus productos, tenga conocimienlos de los registros contables elementales, cuenle con un cierlo nivel educativo que le permita aprovechar los adelantos tecnologicos y eleve su productividad, a fin de que sea capaz de calificar como sujeto de crédito para la Banca Comercial.

En este sentido, la premisa básica es absorber el $10 \%$ de los mi- 
croempresarios existentes en El Salvador por año, mantenerlos por un periodo máximo de tres bajo su prolección y alención, para luego pasarlos a la Banca Comercial como sujelos de crédilo, pero manteniendo el mismo nivel de recursos instilucionales, es decir no crecer patrimonialmente.

\subsubsection{Segunda Alternativa: Absober el mayor número de micro y pequeños empresarlos dotándoles de capltal y asistencla en general, con creclmiento Instituclonal}

Esta segunda allernativa plantea, al igual que la anterior, absober el $10 \%$ de los microempresarios por ańo, pero a diferencia de la anterior, crecer instilucionalmenle, para ampliar la cobertura y prolundizar el proceso de democratización del crédilo.

Con ello se pretende que para el primer ano se puedan absorber el $10 \%$ del tolal existente, para el segundo afo un $20 \%$ y asi sucesivamen. te, hasta llegar a dar la cobertura lotal.

\section{Coriclusiones generales}

Sobre la base del análisis efecluado a lo largo del presente trabajo de investigación podemos concluir lo siguiente:

1) La aplicación de las medidas de liberalización financiera, planteadas por el liberalismo económico, llevados a cabo en una lorma pura y en donde las fuerzas del mercado deben actuar sin ninguna interferencia, no da cabida en El Salvador a las instituciones de Fomento, ya que su existencia exige una participación direcla y activa del Estado. Además, el carácter social que las distingue y tipitica como tales, las hace no buscar la maximización de la rentabilidad, sino realizar esa difícil combinación entre la rentabilidad linanciera y lograr los objetivos de desarrollo.

2) En nuestro país, la gran empresa controla gran parte del capıtal, la producción y el acceso al financiamiento; de ahi que el sistema financiero concentre la concesión de sus crédilos hacia ella. Para evitar este tenómeno es necesario que existan inslituciones que como las de Fomento (FEDECCREDITO, BFA y FIGAPE) se encarguen de proporcionar la asistencia credilicia, capacitación y asesoria en general a aquellos sectores que no son considerados como sujetos de crédito por el Sistema Financiero.

3) Las inslituciones de financiamiento en la Banca de Fomento tal y como han funcionado en la década de los afios 80 , parecen haber respondido en cierto grado al logro de sus objetivos aunque no en torma 
satisfactoria. Dichos objetivos en el área social mostraron únicamente al BFA y FEDECCREDITO con un mejor desempeno manteniendo un Indice de Crecimiento General superior al de la economla. Sin embargo, esta mayor cobertura les significó elevados costos de operación haciéndolas incurrir en pérdidas y volviéndolas ineficientes en el área financiera.

Pero por otra parte, también han existido tactores exógenos a la administración técnica de cada institución que han afectado negativamente y han contribuido para que al final de la década se encuentren mal. Entre ellos podemos conlar la crisis económica en general de Latinoamérica y en especial en El Salvador, el conflicto armado y los desastres nalurales como el terremolo de 1986.

4) En este sentido, para llevar a cabo un proyecto de reorientación en estas instiluciones especializadas, se hace necesario el saneamiento previo de sus carleras, tanto en lo que se refiere a sus activos, que si bien es cierto han tenido tendencias crecientes a lo largo del periodo. también lo han tenido sus pasivos y en algunos anos en una mayor relación. Esto desvirtúa la eficiencia en su desempeno y les ha imposibilitado ampliar la coberlura en su alención a la micro y pequena empresa a fin de capacitarlos y trasladarlos a la Banca Comercial ya como sujelos de crédilo.

5) El rol de la micro y pequena empresa es clave en el proceso de reconslrucción nacional en que se ha embarcado El Salvador, por lo que el Estado no debe dudar en apoyarlos. La contribución de eslos sectores es significaliva ya que son luente de trabajo y abastecedoras de bienes y servicios para el mercado interno, sobre todo de necesidades básicas. Por ello es necesario una reorientación en el funcionamiento de las instiluciones encargadas de darles apoyo a tin de que puedan salir adelante. Prueba de esla urgencia e importancia la constituye la inclusión del crédito para la micro y pequefia empresa formulado en el Capítulo V, numeral 5, lileral b) de los Acuerdos de Chapultepec.

6) Para llevar a cabo esta reorientación, presentamos en esle trabajo tres allernativas siendo ellas: a) La fusión de las tres instituciones aqul consideradas para formar una Banca de Fomenlo Especializada en la atención de la micro y pequeña empresa; b) La fusión de las tres inslituciones pero para formar una Banca Multisectorial en donde se incluyan a estos sectores como opción preferencial y c) Siempre la fusión de las tres instituciones pero para formar una Banca de Segundo Piso.

De estas tres alternalivas, a nuestro juicio la que puede brindar los mejores resullados es la primera, ya que con ello se lograria: la centralización de funciones, optimización en el uso de los recursos tanto male- 
riales como humanos ya existentes, un mayor capilal que permite la ampliación de las operaciones crediticias y, consecuenlemente, una mayor cobertura en el área social ya que se estaría en capacidad de absorber a un mayor número de usuarios del crédito, y un manejo directo de las operaciones que le permitiria un conocimiento y tratamiento más profundo de su sector objelivo.

7) Sin embargo, consideramos que esta modalidad debe ir complementada con la segunda estrategia aquí planteada: absorber un número signiticativo de micro y pequenos empresarios. Entendiéndose por significalivo un $10 \%$ por afto del universo existente, dotándoles de capilal y asistencia para luego trasladarlos ya como sujelos de crédito hacia el mercado tinanciero formal. Este $10 \%$ creemos pueden ser absorbidos por la Banca Comercial, ya que históricamenle en la década analizada, pese a todos los factores adversos, esta Banca Comercial ha mostrado tener la capacidad de generar un crecimiento en igual magnitud en los montos de crédito otorgados.

8) Para finalizar creemos, que la investigación ha presentado los lineamientos generales y da la pauta para realizar posteriores investigaciones que prolundicen en los mecanismos operativos de la propuesta. 